\title{
Modern Ultrasound Diagnostic Procedures in an Interdisciplinary Ultrasound Department: Challenge and Opportunities for Radiologists
}

\section{Moderne Ultraschalldiagnostik in einem interdisziplinären Ultraschall- zentrum: Herausforderung und Chancen für Radiologen}

Authors

Affiliation

\author{
E. M. Jung, C. Stroszczynski
}

Department of Radiology, University Hospital Regensburg, Germany
Key words

interdisciplinary ultrasound department

- contrast enhanced ultrasound (CEUS)

- 3D image fusion

digital imaging

\section{received $\quad 11.12 .2014$} accepted 22.6.2015

\section{Bibliography}

Dol http://dx.doi.org/ 10.1055/s-0041-103463

Published online: 2015

Fortschr Röntgenstr 2016; 188: 27-32 @ Georg Thieme Verlag KG Stuttgart · New York . ISSN 1438-9029

\section{Correspondence}

Prof. Ernst Michael Jung Institut für Röntgendiagnostik, Universitätsklinikum Regensburg Franz-Josef-Strauß-Allee 11 93053 Regensburg Germany

Tel.: ++ 49/941/9447410 Fax: ++ 49/9419447409 ernst-michael.jung@ukr.de

\section{Zusammenfassung \\ $\nabla$}

Interdisziplinäre Ultraschallzentren bilden Kristallisationszentren für eine moderne und effektive Ultraschalldiagnostik. Der Radiologie kommt dabei eine entscheidende Bedeutung durch die Etablierung neuer Untersuchungsmodalitäten zu. Als Beispiel seien die Kontrastmittel-Sonografie (CEUS), die Bildfusion von Ultraschall mit der Computertomografie (CT) und die Magnetresonanztomografie (MRT) sowie das Monitoring bei der Durchführung von Interventionen genannt. Weitere wichtige Aufgabenbereiche stellen die Datenverwaltung und PACS-Anbindung dar.

\section{Abstract \\ $\nabla$}

Interdisciplinary ultrasound departments are sources for modern and effective ultrasound diagnostic procedures. Radiologists have a very important role as part of these centers for the establishment of new diagnostic ultrasound modalities like contrast-enhanced ultrasound (CEUS), image fusion between US and computed tomography (CT) and magnetic resonance tomography (MRI), resulting in new interventional procedures. Data acquisition and the development of solutions for PACS are also important points.

Citation Format:

- Jung EM, Stroszczynski C. Modern Ultrasound Diagnostic Procedures in an Interdisciplinary US Department: Challenge and Opportunities for Radiologists. Fortschr Röntgenstr 2016; 188: 27-32

\section{Introduction}

Interdisciplinary ultrasound centers are typically shaped by the interaction of internal medicine, surgical, and radiology departments in an effort to provide more effective availability of ultrasound services. The integration of additional disciplines significantly expands the areas of application and services. However, there are also new challenges. Radiology at an ultrasound center plays an important role as an interface and nucleus of technical developments for image processing and transmission. Imaging documentation should be performed in DICOM format and with PACS connection. This requires corresponding techniques and standards [1-4].

Perfusion analyses and $3 \mathrm{D}$ als well as $4 \mathrm{D}$ evaluations can be performed on integrated workstations on the basis of the DICOM files. Dynamic examinations include not only color-coded duplex sonography (CCDS) and power Doppler (PD) but also contrast-enhanced ultrasound (CEUS). Moreover, new image documentation is possible as a result of image fusion with computed tomography (CT) and magnetic resonance imaging (MRI). CEUS and fusion can be used to allow implementation, monitoring, and postinterventional follow-up of biopsies, drains, and ablations and can also be used intraoperatively. We present our current experiences at an interdisciplinary ultrasound center (internal medicine, oncology, surgery, plastic surgery, and radiology).

\section{Material \\ $\nabla$}

In a retrospective analysis, the performance data of examination modalities of an interdisciplinary ultrasound center of a maximum care university hospital with 900 beds were recorded on the basis of the data stored in SAP from 2007 to 2014. The organizational chart of the interdisciplinary 
ultrasound center has 2 radiology and internal medicine specialists in managing positions, 2 radiology and surgical resident positions as part of specialist training with a 3-month rotation and 2 nephrology and oncology resident positions as part of specialist training with a 6-month rotation. Ultrasound examinations also include the emergency outpatient unit and 7 intensive care units as well as 1 ultrasound on-call service for special issues, particularly organ transplantation.

Fundamental B-mode examinations, duplex examinations with CCDS and power Doppler, ultrasound elastography, and contrast-enhanced ultrasound (CEUS) are considered separately.

Abdominal examinations were performed with multifrequency convex probes $(1-5 \mathrm{MHz}, 1-6 \mathrm{MHz})$ with the option of CCDS, power Doppler, elastography, and CEUS.Vascular ultrasound was performed with linear probes of $6-9 \mathrm{MHz}, 5-10 \mathrm{MHz}$, and $6-15 \mathrm{MHz}$ also with the option of CEUS and elastography. Contrast-enhanced ultrasound examinations included examinations of organ perfusion, tissue perfusion, characterization of organ tumors, soft tissue tumors and lymph nodes as well as periinterventional and intraoperative examinations. Examinations were performed with $1-5 \mathrm{MHz}$ and 6-9 MHz multifrequency probes. Soft-tissue ultrasound was performed to characterize and detect thyroid tumors in particular, to locate parathyroid adenomas, to evaluate lymph nodes in the case of lymphomas and to evaluate palpable soft tissue tumors with multifrequency probes of up to $15 \mathrm{MHz}$. Vascular ultrasound examinations were performed in particular to diagnose deep leg and arm vein thromboses, arterial hypoperfusion, vascular malformations, as well as periinterventionally with $5-10 \mathrm{MHz}$ and $6-9 \mathrm{MHz}$ multifrequency probes with CCDS, power Doppler, B-flow, and dynamic flow.

Special examinations related to elastography in particular with ARFI measurements in the case of possible liver cirrhosis, periinterventional examinations in the case of radiofrequency ablation (RFA), and intraoperative examinations in the case of liver tumor resection and thyroid tumors and breast tumors. The fusion of CEUS with CT or MRI was requested for the planning and postin-
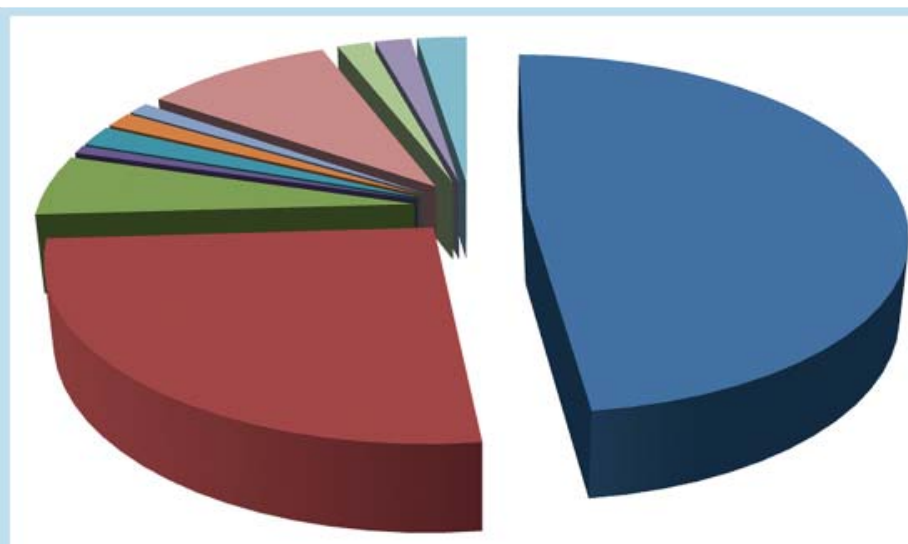

Fig. 1 Example of the ultrasound modalities in 2014 at the interdisciplinary ultrasound center. In the clinical routine, the most common examinations relate to the abdomen ( $49 \%$ ) followed by vascular examinations with duplex sonography (26\%) and ultrasound of the thyroid (4.5\%). Contrast-enhanced ultrasound (CEUS) comprises approx. $10 \%$ of all examinations. Elastography with fibrosis measurement (3\%) and special sonographically guided interventions (1\%) are rare.

Abb. 1 Exemplarische Darstellung der Ultraschallmodalitäten 2014 des interdisziplinären Ultraschallzentrums. Die häufigsten Untersuchungen beziehen sich in der Routine meist auf das Abdomen (49\%), Gefäßuntersuchungen mit der Duplex-Sonografie (26\%) und die Sonografie der Schilddrüse (4,5\%). Die Kontrastmittel-Sonografie (CEUS) beträgt ca. 10 \% der Gesamtuntersuchungen. Selten sind die Elastografie mit Fibrose-Messungen (3\%) und spezielle sonografisch geführte Interventionen (1\%).

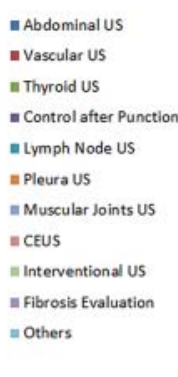

terventional follow-up of percutaneous liver interventions with RFA, TACE, microwave ablation, and for perioperative purposes but also to perform percutaneous interventions of the prostate, e., in the case of biopsy or IRE. ment at the US center.

Findings were documented in an organ-based manner in SAP and images.

\section{Results}

Since 2007, the number of annual examinations has increased from approx. 15000 to 22000 ultrasound examinations on 4 stationary high-performance ultrasound units and 2 mobile ultrasound units with the option of CEUS and elastography ( Fig. 1-3)

Since system utilization is almost $100 \%$ at an interdisciplinary US center and up to $<40 \%$ for other equipment used at wards, this and optimized technical support also contributed to the cost reduction.

US examinations were performed by 2 experienced exami(DEGUM level II, DEGUM level III) and 4 residents training performed by radiologists ( 1 specialist, 1 resident). examinations as part of various screenings, to clarify infection constellations and to perform an expanded tumor search. $25 \%$ of all examinations involve duplex sonography and power Doppler for hemodynamic evaluation of special vascular issues. Special duplex examinations relate to vascular situations after liver, pancreas, kidney transplantation as well as the evaluation of visceral arteries in the case of an issue after mesenteric ischemia and endovascular interventions in abdominal aortic aneurysm. Rarer issues relate to the vascular situation in vascular malformations and the preoperative planning of tissue transplants.

Elastography was performed in $3 \%$ of the approx. 22000 ultrasound examinations with the shear wave technique and ARFI measurements for characterizing tissue consolidations in the case of possible liver cirrhosis. The compound technique was used in $49 \%$ of all thyroid examinations for characterizing focal consolidations. Of the 1027 elastography examinations, $59 \%$ related to the liver, $23 \%$ to the thyroid, $7 \%$ to lymph nodes or soft tissue tumors, and $11 \%$ to other issues, i.e., periinterventional in surgery or RFA. 


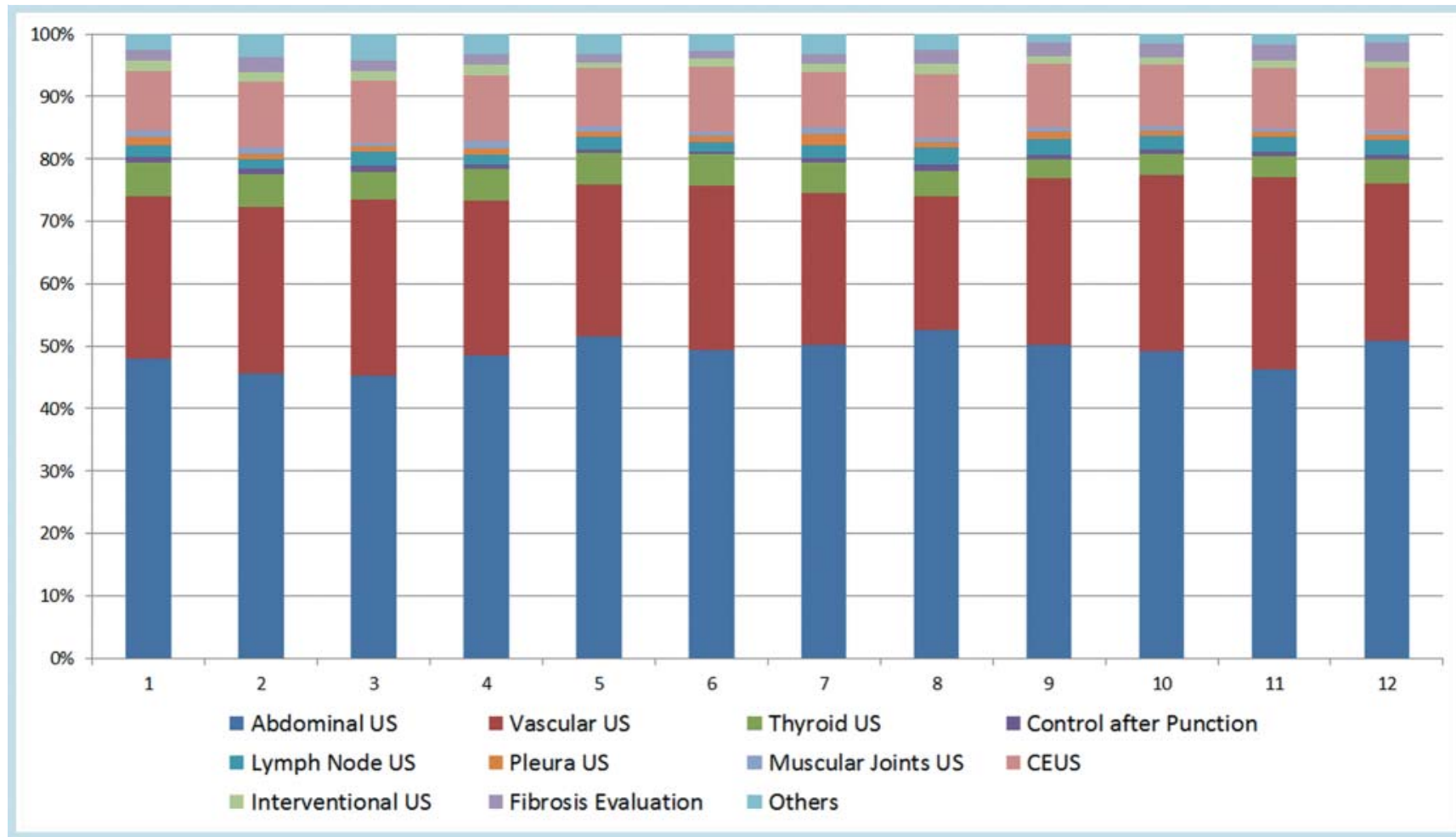

Fig. 2 Evaluation of the frequency in \% of monthly examinations from January (1) to December (12) in 2014 at the interdisciplinary US center. Contrast-enhanced ultrasound (CEUS) comprises up to $10 \%$ of all examinations.

Abb. 2 Evaluation der Häufigkeit in \% der monatlichen Untersuchungen von Januar (1) bis Dezember (12) in 2014 des interdisziplinären US-Zentrums. Anteilig erreicht die Kontrastmittel-Sonografie (CEUS) bis zu $10 \%$ der Gesamtuntersuchungen.

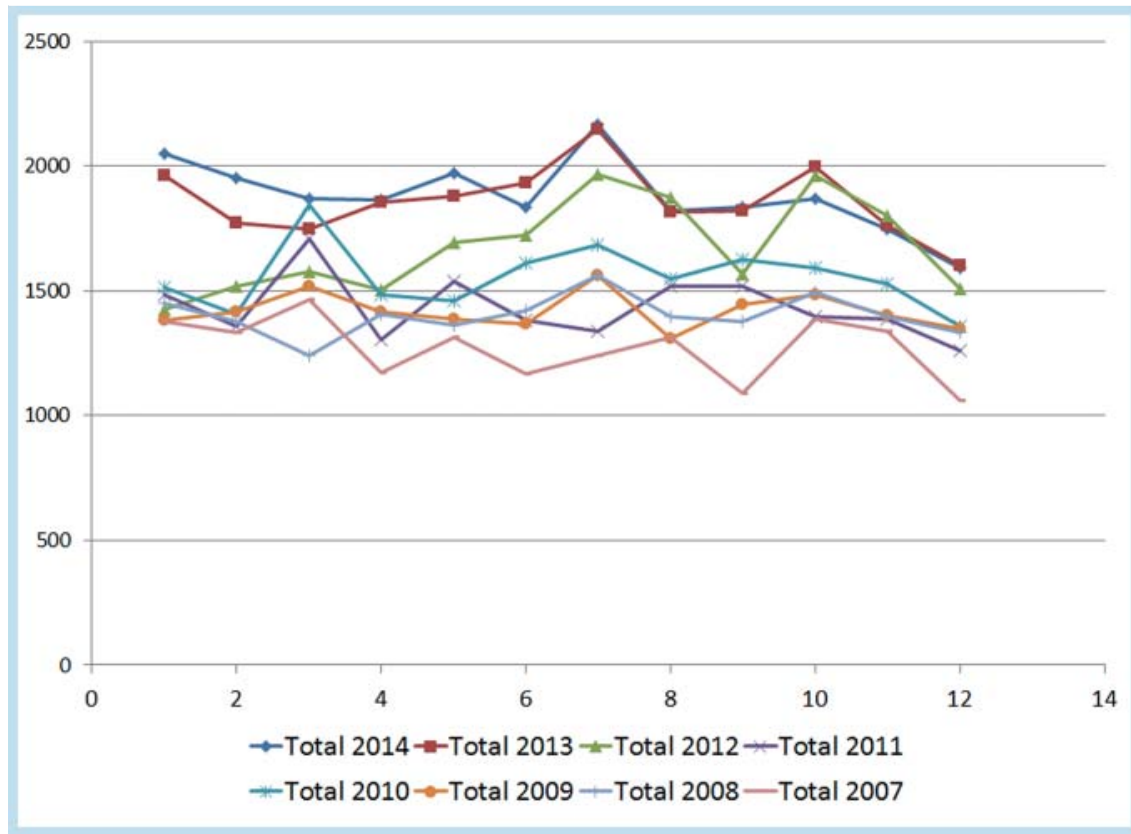

Fig. 3 Trend of ultrasound examinations at the interdisciplinary ultrasound center for the years 2007 to 2014 with recording of the monthly examinations and a continuous increase in examinations from January (1) to December (12).

Abb. 3 Entwicklungen der Ultraschalluntersuchungen des interdisziplinären Ultraschallzentrums im Vergleich der Jahre 2007 bis 2014 mit Erfassung der monatlichen Untersuchungen und der kontinuierlichen Zunahme der Untersuchungen von Januar (1) bis Dezember (12).

The number of contrast-enhanced ultrasound examinations has increased continuously from $1.5 \%$ in 2009 to $10 \%$ of all examinations in 2014. CEUS relates in particular to the detection and characterization of liver tumors and intervention planning for embolization/TACE, RFA and surgical planning ( $\bullet$ Table 1 ).
CEUS is performed at the interdisciplinary ultrasound center exclusively by experienced examiners after obtaining written informed consent if there is no emergency indication, such as in the case of bleeding diagnosis, trauma diagnosis or for intraoperative purposes, by radiology specialists in up to $63 \%$ of cases. 
Contrast-enhanced ultrasound (CEUS) also plays an important role in postinterventional diagnosis. Specific uses of CEUS include time intensity curve (TIC) analysis after tissue transplants for determining capillary microvascularization in the case of malformation and organ hypoperfusion.

Special radiological examinations include the fusion of CEUS with contrast-enhanced CT or MRI or PET-CT. Moreover, special examinations include color-coded perfusion measurements for characterizing tumor metastases, in particular lymph node metastases. Fusion imaging was used in $2.3 \%$ of all examinations in 430 cases and was performed exclusively by radiologists under special requirements for periinterventional or perioperative diagnosis of typically malignant liver tumors for biopsy in $11 \%$ of cases, planning of an expanded or modified resection in $45 \%$ of cases, RFA in $21 \%$, IRE also in the case of prostate CA in $13 \%$ of cases and special requirements including periinterventional requirements in BAA with endostent in $7 \%$ of cases, SIRT in $1 \%$, and other in $2 \%$.

\section{Special radiological ultrasound examinations:}

1. Image fusion US/CEUS with CT/MRI/PET-CT for tumor characterization and intervention planning

2. Volume navigation (Vnav) for percutaneous biopsy and drainage

3. Quantitative perfusion analysis for evaluating transplants such as liver transplants and malformations

Table 1 Indications for contrast-enhanced ultrasound (CEUS).

\begin{tabular}{|c|c|}
\hline & CEUS indications \\
\hline $\begin{array}{l}\text { frequent: } \\
>70 \% \text { of all CEUS requests } \\
\text { by radiology specialist }\end{array}$ & $\begin{array}{l}\text { liver tumor detection } \\
\text { liver tumor characterization } \\
\text { surgical planning for tumors } \\
\text { organ hypoperfusion } \\
\text { characterization of organ infections } \\
\text { control after surgery/RFA/TACE }\end{array}$ \\
\hline $\begin{array}{l}\text { special examinations: } \\
<20 \% \text { of all CEUS } \\
\text { requests } \\
\text { by radiology specialist }\end{array}$ & $\begin{array}{l}\text { intestinal wall microvascularization } \\
\text { characterization of malformations } \\
\text { evaluation after NTx, pancreas Tx } \\
\text { characterization of thyroid and para- } \\
\text { thyroid tumors } \\
\text { periinterventional diagnosis } \\
\text { in biopsies/drains/TACE/RFA } \\
\text { fusion imaging CEUS with CT/MRI/PET }\end{array}$ \\
\hline
\end{tabular}

4. Perfusion analysis for the detection and characterization of SD and NSD tumor

5. Vascular imaging for intervention planning, surgical planning Image archiving is performed when possible digitally as DICOM files in the PACS. In the case of the mobile use of systems in the operating room or intensive care units, the files are stored on hard disks and are then imported into the image archiving system. In routine examinations the necessary data volume is less than 50 megabytes in the case of standard examinations but increases to 1.5 gigabytes in the case of CEUS fusion examinations with the help of PET-CT, volume navigation with GPS and needle guide systems.

The special requirements regarding modern ultrasound in an interdisciplinary ultrasound center already include daily fusion examinations of CEUS with CT or MRI for tumor detection and characterization, examinations with ultrasound elastography with the shear wave technique and ARFI for the evaluation of cirrhotic liver changes and perfusion analysis of tumors with CEUS for intervention planning, i. e., for TACE in HCC ( $\bullet$ Fig. $4-6)$.

\section{Discussion}

The main influence of radiology for an interdisciplinary ultrasound center is the development and integration of modern ultrasound methods and the fastest possible connection to a PACS as well as the inclusion in case and clinical conferences.

The high resolution and the continuous recording of the dynamics of contrast-enhanced ultrasound (CEUS) are used for tumor detection and characterization of tumors with high diagnostic reliability $[5,6]$. In particular for liver tumors, the high diagnostic reliability of CEUS to differentiate benign from malignant tumors and regarding the detection of small tumors that are less than $10 \mathrm{~mm}$ in diameter has been proven in multicenter examinations $[7,8]$.

Regarding the characterization of complicated cystic and solid renal tumors, there is also high diagnostic potential for CEUS [9, $10]$. In general, CEUS is used for the evaluation of microvascularization for all soft tissue and organ tumors accessible to ultrasound $[6,9]$.

However, there are always additional applications also in regard to vascular diagnosis, including the detection of stenoses, aneurysms, fistulas and plaque vascularization $[6,9,11]$.

The fusion of CEUS and CT or MRI or also PET-CT allows new applications for tumor detection and tumor treatment monitoring.

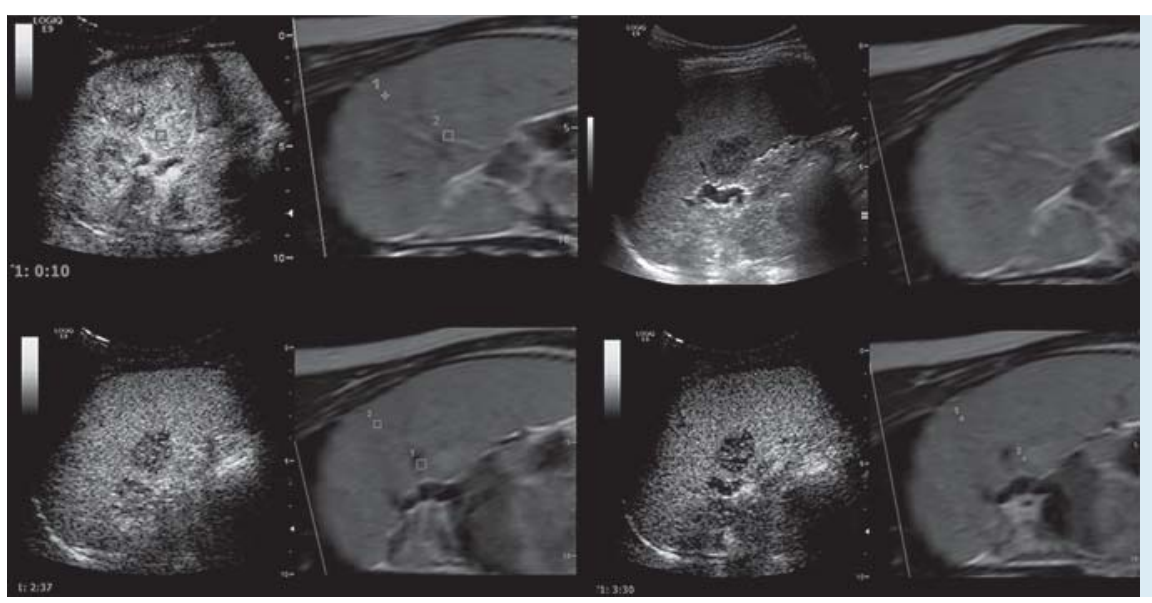

Fig. 4 Fusion for the detection and characterization of liver tumors between contrast-enhanced ultrasound (CEUS) and MRI with modified visualization in angled oblique sections in the case of volume navigation with point registration.

Abb. 4 Fusion zur Detektion und Charakterisierung von Lebertumoren zwischen Kontrastmittelsonografie (CEUS) und MRT mit modifizierter Darstellung in angulierten Schrägschnitten bei Volumennavigation mit Punktregistrierung. 


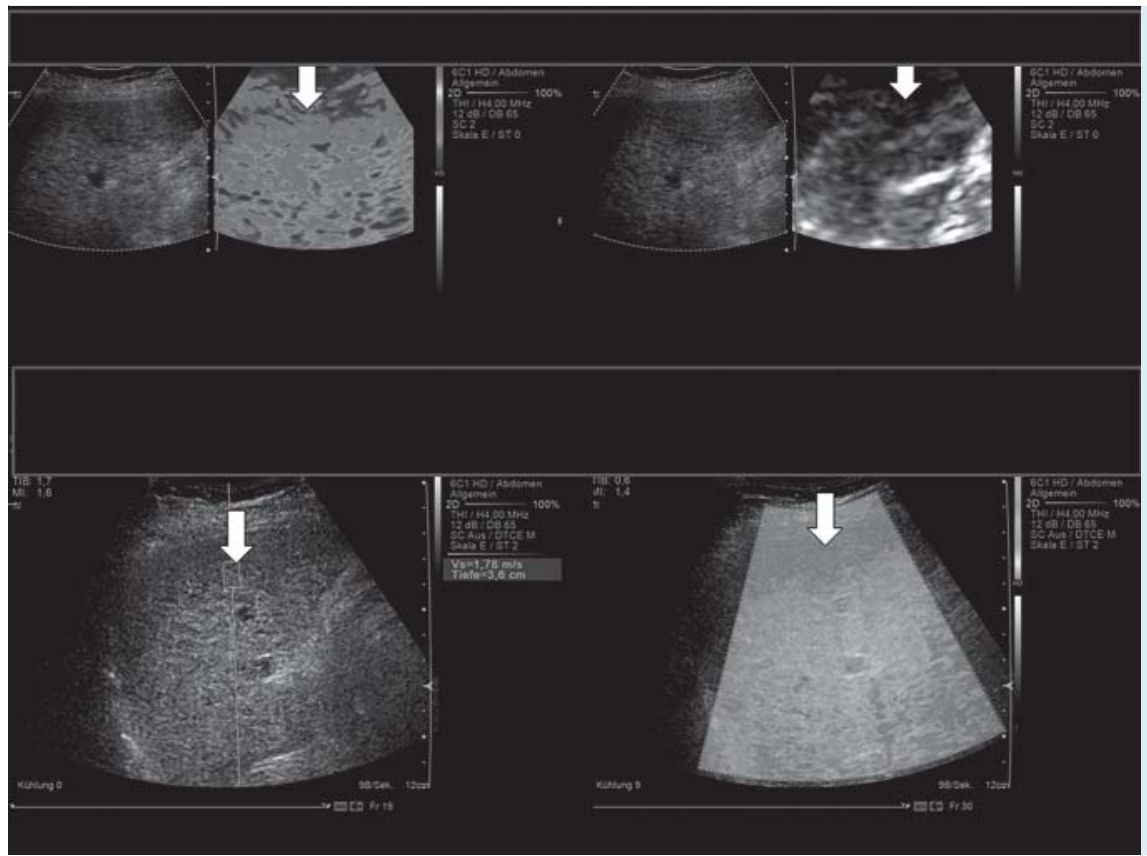

Fig. 5 Evaluation of an inhomogeneous liver with ultrasound elastography using compression technique (top) and automated shear wave technique with ARFI measurement (bottom).

Abb.5 Beurteilung einer echoinhomogenen Leber mit der Ultraschallelastografie in Kompressionstechnik (oben) und automatisiert in Shear-WaveTechnik mit ARFI-Messung (unten).

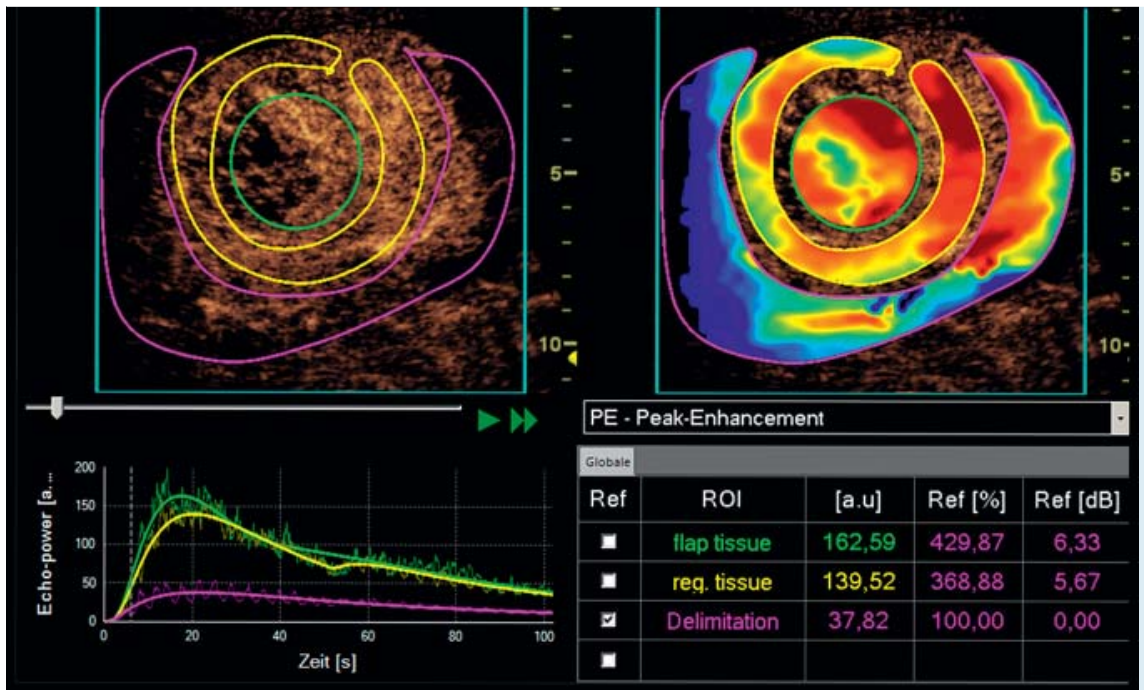

Fig. 6 Visualization of a hepatocellular carcinoma (HCC) with CEUS and perfusion analysis, color-coded and semiquantitative with perfusion analysis. Significant arterial hypervascularization in the tumor center and periphery with high peak enhancement values.

Abb. 6 Darstellung eines hepatozellulären Karzinoms (HCC) mit CEUS und Perfusionsanalyse, farbkodiert und semiquantitativ mit Perfusionsanalyse. Deutliche arterielle Hypervaskularisation im Tumorzentrum und Randbereich mit hohen Werten des Peak-Enhancement.

Therefore, CEUS is used particularly preinterventionally and postinterventionally in TACE, RFA, and IRE as well as intraoperatively, of course also for biopsies and drains as necessary [1, 12 - 15]. In our own patient collective, the indications for CEUS for intervention preparation, postinterventional follow-up, and intraoperative use particularly in liver tumors have increased significantly during recent years. Special applications include the characterization of malformations and the characterization of thyroid and parathyroid tumors $[1,3,4,9]$.

Many CEUS examinations constitute off-label use even though there are "non-liver guidelines" [6]. CEUS is also increasingly used in children since it can be performed quickly and no special sedation is necessary. If sulfur hexafluoride microbubbles (Sono$V_{u e^{\circledR}}$ ) are used, CEUS can also be used in renal insufficiency. Repeat applications are possible. Fusion with navigation is being tested for difficult interventions. $3 \mathrm{D} / 4 \mathrm{D}$ applications are special requirements and are thus subject to volumetry.
Different US elastography techniques are increasingly available. US elastography is increasingly used in particular in the characterization of soft tissue processes and lymph node metastases and in thyroid changes. Its use for intervention monitoring also seems promising $[1,3,4]$.

In fusion imaging, the advantages of different imaging modalities are utilized to facilitate intervention planning in particular. CEUS can dynamically visualize themicrovascularization of tumors. Contrast agent application is not limited. This can be helpful in the case of renal insufficiency or other contrast agent intolerances for CT and MRI for intervention planning in RFA, TACE, IRE, and SIRT [16] but also for post-interventional follow-up.

However, difficult punctures can also be performed with fusion US with CT or MRI and volume navigation. The expertise of radiologists with the different imaging modalities has proven to be essential particularly in this area [12].

Data storage and additional evaluation with perfusion programs are still under development. Special workstations are increasingly 
integrated in high-end equipment. The possibility to test all new technical developments with respect to their clinical analysis options is one of the many challenges for interdisciplinary US centers. Integrating these developments in training is an important aspect for modern specialist training.

\section{References}

1 Clevert DA, Jung EM. Interventional sonography of the liver and kidneys. Radiologe 2013; 53: 962 -973

2 Fischer T, Sack I, Thomas A. Characterization of focal breast lesions by means of elastography. Fortschr Röntgenstr 2013; 185: 816-823

3 Jung EM, Stroszczynski C. A 1st evaluation by the Ultrasound Professional Society, AGUS - ultrasound update radiology. Fortschr Röntgenstr 2014; 186: 545-548

4 Jung EM, Stroszczynski C. Ultrasonic AG - contrast-enhanced (CEUS) in radiology: A preliminary analysis and critical evaluation of AGUS. Fortschr Röntgenstr 2014; 186: 417-419

5 Claudon M, Dietrich CF, Choi BI et al. Guidelines and good clinical practice recommendations for Contrast Enhanced Ultrasound (CEUS) in the liver - update 2012: A WFUMB-EFSUMB initiative in cooperation with representatives of AFSUMB, AIUM, ASUM, FLAUS and ICUS. Ultrasound Med Biol 2013; 39: 187-210

6 Piscaglia F, Nolsoe C, Dietrich CF et al. The EFSUMB Guidelines and Recommendations on the Clinical Practice of Contrast Enhanced Ultrasound (CEUS): update 2011 on non-hepatic applications. Ultraschall in Med 2012; 33: 33-59

7 Seitz K, Bernatik T, Strobel D et al. Contrast-enhanced ultrasound (CEUS) for the characterization of focal liver lesions in clinical practice (DEGUM Multicenter Trial): CEUS vs. MRI-a prospective comparison in 269 patients. Ultraschall in Med 2010; 31: $492-499$

8 Strobel D, Bernatik T, Blank $W$ et al. Diagnostic accuracy of CEUS in the differential diagnosis of small $(</=20 \mathrm{~mm})$ and subcentimetric $(</=10 \mathrm{~mm})$ focal liver lesions in comparison with histology. Results of the DEGUM multicenter trial. Ultraschall in Med 2011; 32: 593 - 597
9 Clevert DA, D'Anastasi M, Jung EM. Contrast-enhanced ultrasound and microcirculation: efficiency through dynamics-current developments. Clin Hemorheol Microcirc 2013; 53: 171 - 186

10 Clevert DA, Minaifar N, Weckbach S et al. Multislice computed tomography versus contrast-enhanced ultrasound in evaluation of complex cystic renal masses using the Bosniak classification system. Clin Hemorheol Microcirc 2008; 39: 171 - 178

11 Greis C. Quantitative evaluation of microvascular blood flow by contrast-enhanced ultrasound (CEUS). Clin Hemorheol Microcirc 2011; 49: $137-149$

12 Jung EM, Schreyer AG, Schacherer D et al. New real-time image fusion technique for characterization of tumor vascularisation and tumor perfusion of liver tumors with contrast-enhanced ultrasound, spiral CT or MRI: first results. Clin Hemorheol Microcirc 2009; 43: 57-69

13 Ross $C J$, Rennert J, Schacherer $D$ et al. Image fusion with volume navigation of contrast enhanced ultrasound (CEUS) with computed tomography (CT) or magnetic resonance imaging (MRI) for post-interventional follow-up after transcatheter arterial chemoembolization (TACE) of hepatocellular carcinomas (HCC): Preliminary results. Clin Hemorheol Microcirc 2010; 46: 101-115

14 Wiggermann $P$, Wohlgemuth WA, Heibl M et al. Dynamic evaluation and quantification of microvascularization during degradable starch microspheres transarterial Chemoembolisation (DSM-TACE) of HCC lesions using contrast enhanced ultrasound (CEUS): a feasibility study. Clin Hemorheol Microcirc 2013; 53: 337-348

15 Wobser H, Wiest R, Salzberger B et al. Evaluation of treatment response after chemoembolisation (TACE) in hepatocellular carcinoma using real time image fusion of contrast-enhanced ultrasound (CEUS) and computed tomography (CT)-preliminary results. Clin Hemorheol Microcirc 2014; 57: 191 - 201

16 Rennert J, Georgieva M, Schreyer AG et al. Image fusion of contrast enhanced ultrasound (CEUS) with computed tomography (CT) or magnetic resonance imaging (MRI) using volume navigation for detection, characterization and planning of therapeutic interventions of liver tumors. Clin Hemorheol Microcirc 2011; 49: 67-81 